\title{
La recategorización del adverbio medio en español*
}

\author{
Enrique Pato** \\ Universidad de Montréal, Canada
}

\begin{abstract}
Resumen
De acuerdo con las gramáticas descriptivas tradicionales, medio es una categoría variable. Puede ser un nombre (medio de vida), un adjetivo numeral (cuantificador) (media docena) o un adverbio (estaba medio cansado). Toma la forma invariable como adverbio en español estándar (estaba medio cansada), pero cuando el adverbio concuerda con el adjetivo al que modifica (estaba *media cansada) se considera un uso no estándar. Numerosos casos han sido documentados donde el adverbio medio concuerda, como si fuera un adjetivo, con el nombre o con el adjetivo que modifica. Este proceso, conocido como 'recategorización' implica que un elemento es interpretado como perteneciente a una categoría (i.e. adjetivo) en una variedad y como parte de otra categoría (en este caso, adverbio) en otra variedad. La 'adjetivización' de medio es ampliamente considerada como característica de las variedades del español americano, pero se ha creído de uso ocasional en el español peninsular. En este trabajo emplearé los datos dialectales inéditos del ALPI (Atlas Lingüístico de la Península Ibérica) para examinar el área geográfica precisa
\end{abstract}

${ }^{*}$ Mi agradecimiento a Inés Fernández-Ordóñez (RAE/UAM) por los comentarios que realizó al manuscrito preliminar.

** Para correspondencia, dirigirse a: Enrique Pato (enrique.pato-maldonado@umontreal. ca ), Département de littératures et de langues modernes, Université de Montréal, C.P. 6128, succursale Centre-ville, Montréal, (Québec) H3C 3J7, Canada. 
del fenómeno en español peninsular. Los datos muestran claramente que la distribución es mucho más amplia de lo que previamente se pensaba, puesto que se registra no solo en Galicia, sino también en la zona leonesa y en Andalucía, esta última podría interpretarse como la fuente probable de transferencia en las variedades americanas. Además, empleo datos históricos y contemporáneos tanto de autores peninsulares como americanos (gracias al Corpus del español) para analizar algunos casos específicos del adverbio medio con y sin concordancia (medio/media tonta), y para estudiar las interpretaciones semánticas asociadas con cada variante.

Palabras clave: español, recategorización, Atlas Lingüístico de la Península Ibérica, adverbio, medio.

The ReCATEgorization of THE ADVERB MEDio IN Spanish

\begin{abstract}
According to traditional descriptive grammars, Spanish medio ('half') is a variable category. It can be a noun (medio de vida), a numeral adjective (quantifier) (media docena), or an unstressed adverb (estaba medio cansado). However, medio takes an invariable form as an adverb in standard Spanish (estaba medio cansada). Making the adverb medio agree with the adjective it modifies (estaba *media cansada) is considered nonstandard. Numerous cases are attested where the adverb medio agrees, as though it were an adjective, with the noun or the adjective which it modifies. This process, known as 'recategorization' implies that an element is interpreted as belonging to one category (i.e. adjective) in some varieties and as part of another (here, adverb) in other varieties. The 'adjectivization' of medio is widely considered to be characteristic of Latin American Spanish varieties, but it is believed to be rare in Iberian Spanish. In this study I use unpublished dialect data from the ALPI (Atlas Lingüistico de la Península Ibérica) to examine the precise geographical area of the phenomenon in Peninsular Spanish. These data clearly show that the distribution of this phenomenon is much wider than previously claimed, since it is attested not only in the Galician area but also in Leonese and in Andalusian, the latter being the probable source for the transfer of the phenomenon to Latin American Spanish. We also use historical and contemporary data from both Peninsular and Latin American texts (Corpus del español) to analyse some specific cases of adverbial medio with and without agreement (medio/media tonta), and to study the semantic interpretations associated with each variant.
\end{abstract}


Key words: Spanish, recategorization, Atlas Lingüistico de la Península Ibérica, adverb, medio.

Recibido: 14/07/10. Aceptado: 09/09/10.

\section{INTRODUCCIÓN}

En casi todos los tratados de gramática española (desde Bello 1847) medio aparece descrito como una categoría variable. Así, puede ser nombre (cf. 1a), adjetivo numeral con el significado de 'igual a la mitad de una cosa' (cf. 1b) o 'que está intermedio en lugar o tiempo' (cf. 1c), y adverbio átono invariable con el significado de 'no del todo' (cf. 1d):

(1) a. Es mi medio de vida. Se vale de malos medios.

b. Hay media docena. Se comió medio pollo asado.

c. Estamos a medio camino.

d. Estaba medio cansado/ medio cansada. El pollo está medio asado $^{1}$.

Ni como nombre y ni como adjetivo medio presenta problemas o divergencias en la gramática del español. Es sabido que los nombres discontinuos admiten el cuantificador medio (media silla), pero no los continuos (*medio aire) (cf. Bosque 1999b), que siendo adjetivo concuerda en género con el nombre que designa a la unidad (cf. 1b), y que puede aparecer en número plural, siempre que vaya acompañado de un cardinal (cf. 2):

(2) a. ya que estaba para expirar, en la cámara le tenían puesto un candelero de plata con una vela, y llegó uno, no hallando ya otra cosa, le quitó y se lo llevó poniéndole la candela entre dos medios ladrillos, y desta suerte acabó sus días [La descripción de las Indias, Reginaldo de Lizárraga (1569)].

\footnotetext{
1 Además, puede tener valor hiperbólico (Medio Madrid está en los toros, Lo sabía medio España) cuando el adverbio se adjetiviza, o estar lexicalizado (mediodía, medialuna, media pensión, medias palabras) (cf., entre otros, Bello 1847 y Meyer-Lübke 1899).
} 
b. Ordinariamente no fumaba; pero si tenía este vicio, fumaba cuatro medios cigarrillos al día, dos por la mañana y dos por la tarde, uno de ellos al medio y otro a la conclusión de la tarea [Tipos y paisajes, José $\mathrm{M}^{\mathrm{a}}$ de Pereda (1870)].

Sin embargo, como adverbio medio debe ser invariable y no puede concordar con el adjetivo (*estoy media cansada, cf. RAE 1972 y 2005, Quilis 1983: 36). A pesar de esta prescripción académica, existen numerosos casos donde el adverbio medio concuerda, como adjetivo, con el nombre o con el adjetivo al que acompaña (media muerta, medios hermanos). Este proceso, conocido con el nombre de recategorización, implica -desde el punto de vista léxico-sintáctico-que un elemento se interprete en una variedad como una categoría (en nuestro caso como un adjetivo) y en otras variedades como otra categoría (adverbio). La idea general que se ha mantenido acerca de la 'adjetivización' de medio ${ }^{2}$ es que su uso es característico y rasgo propio de las variedades del español americano, y así se ha ido repitiendo en casi todos los trabajos (cf. Alonso 1961: 47, Corominas 1980, Moreno de Alba 1993: 190, etc.).

Algunos autores lo han registrado únicamente para el español de Chile (Bello y Cuervo 1988: 139, n. 371: la niña salió media desnuda; quedaron medios muertos) o Colombia (Cuervo 1885: 257) y otros (cf. Kany 1945: 55, Graell y Quilis 1991), por el contrario, señalan que su uso no se encuentra confinado a ninguna región en particular y consideran que es "corriente en todas partes en el habla popular", ofreciendo algunos ejemplos literarios de Argentina, Uruguay, Paraguay, Chile ${ }^{3}$, Perú, Ecuador, Guatemala, México, Santo Domingo, Puerto Rico y Panamá ${ }^{4}$.

2 La discusión del estatuto gramatical propio de medio (como cuantificador adjetival, adverbio de grado, adverbio declinado, etc.) no forma parte de los objetivos principales de este trabajo. Nos limitaremos, por ello, a señalar que puede ser tratado simplemente como un adverbio adjetival (cf. Bosque 1990: 130, Pato y Heap 2005, RAE 2010).

3 Según indica Kany (1962: 136 y 239), en Chile además se emplea medio para indicar tamaño grande: ¡Qué media casa! = ¡Qué casa más grande!; ¿Te acorday, Juan, la media fiestecita qu'hice cuando ustees se comprometieron? (Árbol viejo, Acevedo Hernández, 1927).

4 El trabajo de Graell y Quilis (1991) es el único estudio consultado en donde aparece tratado con cierto detalle el fenómeno que nos ocupa. Los autores analizaron la concordancia del adverbio medio a través del siguiente cuestionario: a. mi hermano es medio tonto; b. mis hermanos son medios tontos; c. mi hermana es media tonta; d. mis hermanas son medias tontas. Los resultados finales mostraron que, en Panamá, la variación es notable, puesto que la creencia de uso permite: 1) la concordancia en todos los casos, 2) solo en el femenino (tanto singular como plural), 3) solo en el femenino singular, y 4) solo en el masculino plural. El 
En la Península Ibérica, por otro lado, este empleo de medio 'recategorizado' ha pasado inadvertido o ha sido tratado de "no común". No obstante, se ha registrado en leonés (bajo la forma meyo/meyu, cf. Corominas 1980: 320) y en Canarias (cf. Quilis 1983: 36, ando media loca). Donde sí es de aparición regular es en gallego-portugués (bajo la forma meio/meia), de ahí que el "uso concordado" haya sido descrito como característico del castellano hablado en Galicia (cf. Cotarelo 1927: 97, Rabanal 1967: 43, García 1985: 122, Seco 1986: 257 y Rojo 2004: 1095) $)^{5}$.

En el presente trabajo nos proponemos estudiar, por un lado y gracias a los datos inéditos del Atlas Lingüístico de la Península Ibérica (ALPI), hasta la fecha el único atlas que permite una comparación por provincias y áreas lingüísticas de manera global, la extensión geográfica precisa del fenómeno en el castellano peninsular. Conoceremos su distribución (vid. Mapa 1) y trazaremos las posibles relaciones de su aparición en el español americano. La documentación en textos modernos y antiguos, por otro lado, nos permitirá comprobar que el fenómeno presenta raíces históricas evidentes, que poco o nada se habían investigado, y mostrar que la variación es más común de lo que en principio se había pensado. Un primer análisis del proceso de recategorización sufrido por medio, junto con su interpretación semántica, conformará la última parte del trabajo.

\section{LA EXTENSIÓN DE MEDIO/ MEDIA EN LA PENÍNSULA IBÉRICA, SEGÚN LOS DATOS DEL ALPI}

Como ha quedado señalado, estableceremos una doble documentación del fenómeno en estudio con los ejemplos registrados en varios textos (obtenidos

factor 'origen' no parece ser determinante, ya que tanto informantes cultos como no cultos lo aceptan y/o rechazan, dando lugar, de nuevo, a una gran variedad de situaciones: a) informante culto de Jaqué y de Colón, pero también informantes no cultos de Santiago y Changuinola aceptan la concordancia en todos los casos, b) informante no culto de Jaqué, Colón, Panamá y Las Tablas, y cultos de David y Changuinola en el femenino, tanto singular como plural, c) informante culto de Panamá solo el femenino singular, d) informante no culto de David en el masculino plural, y e) el uso correcto, sin variación alguna de medio, es propio de los hablantes cultos de Santiago de Veraguas.

5 En otras lenguas, como en italiano (mezo, mezza) o en inglés (she's half crazy 'está medio loca'> adv.; half a dozen eggs/ a half-dozen eggs 'media docena de huevos'> adj.) podemos encontrar una situación similar. 
en el Corpus del español de Mark Davies), por una parte, y con los datos del Atlas Lingüistico de la Península Ibérica (ALPI), por otra.

Por lo que respecta a la información del ALPI (Cuaderno I, \#406. Estaba medio dormida), la forma vernácula (media dormida) se ha podido registrar, por provincias (cf. Tabla 1 infra) en Coruña (puntos 100-112), Pontevedra (128-140), Orense (141-151, salvo 148), Lugo (116, 118, 121-126), León (324.Ponte de Rey, 325. Lillo de Bierzo y 333.Castroquilame), Zamora (337. San Ciprián de Sanabria, 338.San Martín de Castañeda, 340.Padornelo y 341.Hermisende), Valladolid (435.Villavicencio de los Caballeros y 436.San Cebrián de Mazote), Salamanca (355.Serradilla del Arroyo, 356.Linares de Riofrío y 358.El Payo), Cáceres (361.Pinofranqueado), Huelva (519.Alonso y 521.Villablanca), Sevilla (525.Cantillana, 526.Bormujos, 527.Fuentes de Andalucía, 529.El Coronil y 531.Lebrija), Cádiz (532.El Bosque, 533. Chiclana de la Frontera, 534.Alcalá de los Gazules y 535.Tarifa), Málaga (540.Manilva), Albacete (485.Higueruela), Murcia (566.Abanilla y 570. Cabo de Palos), Almería (560.Mojácar), Toledo (469.El Romeral) y Huesca (607.Torla) ${ }^{6}$.

En el siguiente mapa se puede apreciar la distribución de medio / media en la Península Ibérica (zona castellana y Galicia).

Mapa 1. Extensión de medio / media en el castellano, según los datos del ALPI

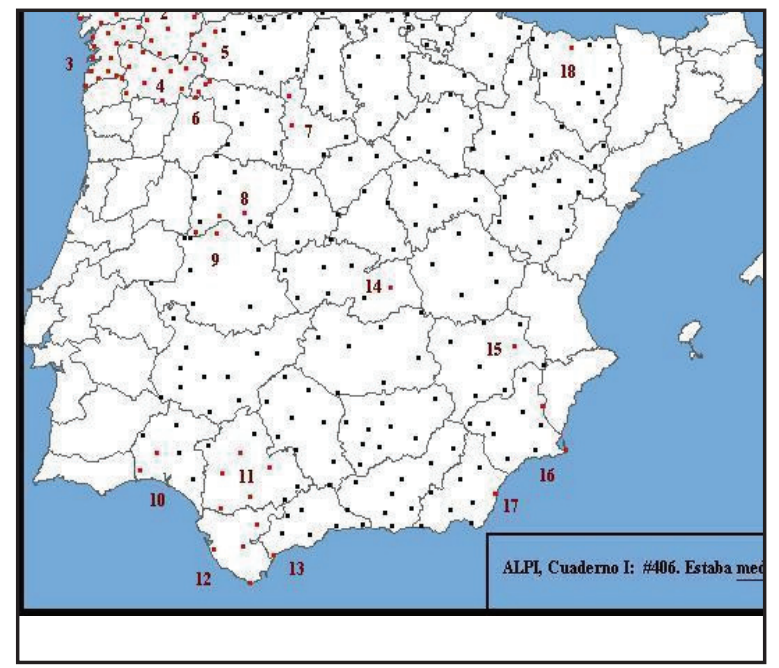

6 Está ausente, por tanto, de los enclaves de Cantabria, Palencia, Burgos, Segovia, Ávila, Vizcaya, Álava, Navarra, La Rioja, Soria, Teruel, Zaragoza, Madrid, Guadalajara, Cuenca, Ciudad Real, Badajoz, Córdoba, Jaén y Granada. En Asturias se emplea la forma mediu. 
En la Tabla 1, como complemento del Mapa 1, aparece recogida la información suministrada por el ALPI. Después de la primera columna (Provincias) figura el porcentaje de aparición de la forma estándar (medio), de la forma vernácula (media), los casos de variación (medio/media), el número de enclaves sin datos y el número total de puntos encuestados en cada provincia.

Tabla 1. Datos del ALPI, Cuaderno I: \#406. Estaba medio dormida

\begin{tabular}{|c|c|c|c|c|c|}
\hline \multicolumn{6}{|c|}{ Enclaves } \\
\hline Provincias & $\begin{array}{l}\text { Estándar } \\
\text { (medio) }\end{array}$ & $\begin{array}{l}\text { Vernácula } \\
\text { (media) }\end{array}$ & $\begin{array}{l}\text { Variación } \\
\text { (medio } \sim a)\end{array}$ & $\begin{array}{l}\text { Sin dato } \\
\text { (ø) }\end{array}$ & Total \\
\hline 1. Coruña & --- & $14(\mathbf{1 0 0 \%})$ & --- & --- & 14 \\
\hline 2. Lugo & $6(42.86 \%)$ & $8(57.14 \%)$ & --- & --- & 14 \\
\hline 3. Pontevedra & --- & $13(\mathbf{1 0 0 \%})$ & --- & --- & 13 \\
\hline 4. Orense & --- & $9(\mathbf{8 1 . 8 2 \%})$ & $1(9.09 \%)$ & $1(9.09 \%)$ & 11 \\
\hline 5. León & $10(76.92 \%)$ & $2(15.38 \%)$ & $1(7.69 \%)$ & --- & 13 \\
\hline 6. Zamora & $8(66.67 \%)$ & --- & $4(33.33 \%)$ & --- & 12 \\
\hline 7. Valladolid & $2(50 \%)$ & $2(50 \%)$ & --- & --- & 4 \\
\hline 8. Salamanca & $8(72.73 \%)$ & $2(18.18 \%)$ & $1(9.09 \%)$ & --- & 11 \\
\hline 9. Cáceres & $6(75 \%)$ & $1(12.50 \%)$ & --- & $1(12.50 \%)$ & 8 \\
\hline 10. Huelva & $4(66.67 \%)$ & $2(33.33 \%)$ & --- & --- & 6 \\
\hline 11. Sevilla & $4(44.44 \%)$ & $5(55.56 \%)$ & --- & --- & 9 \\
\hline 12. Cádiz & --- & $4(\mathbf{1 0 0 \%})$ & --- & --- & 4 \\
\hline 13. Málaga & $7(87.50 \%)$ & $1(12.50 \%)$ & --- & --- & 8 \\
\hline 14. Toledo & $6(85.71 \%)$ & $1(14.29 \%)$ & --- & --- & 7 \\
\hline 15. Albacete & $7(87.50 \%)$ & $1(12.50 \%)$ & --- & --- & 8 \\
\hline 16. Murcia & $7(70 \%)$ & $2(20 \%)$ & --- & $1(10 \%)$ & 10 \\
\hline 17. Almería & $7(87.50 \%)$ & $1(12.50 \%)$ & --- & --- & 8 \\
\hline 18. Huesca & $12(92.31 \%)$ & $1(7.69 \%)$ & --- & --- & 13 \\
\hline Totales & $94(54.34 \%)$ & $69(39.88 \%)$ & $7(4.05 \%)$ & $3(1.74 \%)$ & 173 \\
\hline
\end{tabular}

Los datos del ALPI son, como siempre, de gran interés. De manera resumida, y gracias al Mapa 1, podemos comprobar que existen dos grandes zonas en donde es posible registrar la forma vernácula (media dormida): una primera en el norte, en Galicia (provincias de Coruña, Pontevedra, Orense 
y Lugo) y enclaves afines de León y Zamora, y una segunda en el sur, en la Andalucía occidental (provincias de Cádiz, Sevilla, Huelva y Málaga). No obstante, la documentación del fenómeno se da también al noroeste de Valladolid y en los enclaves fronterizos entre Salamanca y Cáceres. En el resto de las provincias, es el caso de Toledo, Albacete o Huesca, parece ser esporádica.

La visión ofrecida por el Mapa 1 puede ser completada con los datos de la Tabla 1, que nos muestran, además que: a) aunque la forma vernácula obtiene un porcentaje global elevado importante, de casi el $40 \%$, es la forma estándar la que presenta un porcentaje mayor (del 54\%); b) Coruña, Pontevedra y Orense, al norte, y Cádiz, al sur, son las provincias con porcentajes de aparición más altos (del 82-100\%); c) existe un comportamiento 'diferente' en la provincia Lugo (57.14\%), con respecto al resto de las provincias gallegas, que puede ser explicado gracias a la distribución del fenómeno. En efecto, según aparece reflejado en el Mapa 1, son los enclaves situados al oriente de Lugo, aquellos que están más cerca de la vecina Asturias $(114,115,117,119,120$ y 127) los que no reflejan el uso vernáculo; y d) es posible documentar la variación (medio/media dormida) en el habla de un mismo informante, y que estos casos se documentan en las provincias de Orense (enclave 148), León (333), Zamora (337, 338, 340 y 341) y Salamanca (355) ${ }^{7}$.

Por otro lado, el ALPI nos puede aportar información nueva acerca de la presencia del fenómeno en América, ya que podría explicarse, en parte, como una extensión de la teoría andalucista del español americano (vid. la vieja polémica entre Wagner 1920, 1927 y Henríquez Ureña 1925, y los trabajos de Alonso 1961, Menéndez Pidal 1962, Lapesa 1964, entre otros, que defienden una nivelación de variantes frente a la base andaluza del español americano).

En efecto, como ya indicó Menéndez Pidal (1962), las primeras emigraciones hacia el Nuevo Continente salieron del sur del reino (Extremadura, Canarias y, sobre todo, Andalucía), y serían la comunicación colonial con la metrópoli, por un lado, y el carácter comercial, por otro, los factores que explicarían la repartición de los tipos de habla hispanoamericana: el popular (más andalucista) y el cortesano. No debemos olvidar además que Sevilla y Cádiz monopolizaron el comercio y las relaciones con Indias durante los siglos XVI y XVII, y que la participación andaluza fue

7 Hay que indicar que en algunos enclaves de León, Zamora y Cáceres, junto a la forma media, se registra también la forma vernácula mediu/ meyu. 
mayoritaria ${ }^{8}$. De ahí que para Lapesa (1964), por ejemplo, no haya duda posible del origen andaluz de ciertos rasgos fonético-fonológicos propios del español americano: como el seseo, el yeísmo, la alternancia -r/-1, la aspiración de -s, y la j/h aspirada, pero como fenómenos propios no solo en Andalucía, sino también en otras regiones meridionales, como Extremadura. Por tanto, lo 'andaluz' debería tomarse como uno de los diversos elementos que entraron en su formación, es decir, los fenómenos hispanoamericanos serían paralelos a los andaluces, pero no descendientes de ellos.

Para otros autores, en cambio, por ejemplo Alonso (1961), los rasgos del español en América serían el resultado de un proceso de innovación propia, y la base lingüística sería la nivelación realizada por los expedicionarios durante todo el siglo XVI, pues en la colonización de América intervinieron gentes de muchas regiones españolas, de ahí la aparición de elementos regionales hispanos muy diversos en el español hablado en América, como por ejemplo la abundancia de occidentalismos o voces leonesas y gallegas en el léxico hispanoamericano (cf. Cuervo 1998[1886]).

Por todo ello, creemos que este regionalismo (la preferencia por media/ medios en lugar de medio) se pudo generalizar en las variedades americanas gracias a que constituía un elemento común, coincidente en andaluz y en el castellano de Galicia, y a que podía estar presente en otras provincias. De ahí que podamos concluir con Lapesa (1964) que lo singular del español americano es la presencia conjunta de rasgos que en España aparecen disgregados, combinados con indigenismos, con supervivencias e innovaciones hasta cierto punto 'extrañas' a los hábitos peninsulares de hoy.

\section{LA DOCUMENTACIÓN DEL FENÓMENO: EJEMPLOS DE VARIACIÓN MEDIO/ MEDIA}

En este apartado presentaremos algunos ejemplos de variación, documentados tanto en textos medievales y peninsulares como en textos americanos, siguiendo un criterio puramente léxico: deidades (cf. los

\footnotetext{
8 Esta idea fue aclarada posteriormente por Boyd-Bowman (cf. la última referencia de 1985), al mostrar que en los primeros años de la colonización (1493-1508) el 60\% de los que pasaron a Indias eran andaluces. El número de pobladores identificados por este autor es el siguiente: Sevilla/Triana 10.638, Guadalcanal (Sevilla) 390, Écija (Sevilla) 320, Jerez de la Frontera (Cádiz) 626, Sanlúcar de Barrameda (Cádiz) 270, Palos-Moguer (Huelva) 605 y Málaga 237.
} 
ejemplos de 3), adjetivo desnudo (cf. 4) y términos de parentesco (cf. 5$6)$.

(3) a. por aquella bien andança en que se alli ueyen; llamaron a sos cabdiellos semideos que quiere dezir medio dioses [Estoria de España I, Alfonso X].

b. en menosprecio de la deesa Ceres mandó cortar una encina o alcornoque donde las ninfas y otros medio dioses se ayuntaban a hacer sus fiestas, por ser árbol consagrado [Philosofía secreta, Juan Pérez de Moya (1554)].

c. Otros dioses había que se decían semideos, o medioxumos, que quiere decir medios dioses [Philosofía secreta, Juan Pérez de Moya (1554)].

(4) a. Vnos ommes peregrinos llegaron al abad ysaac pediendole limosna \& trayan vestiduras rotas que pareçien medio desnudos e demandandole que les diesse de vestir [Exemplario por $A B C$ ].

b. cargaban todos sobre los tristes hombres que solos en la isla habían quedado; y muchos andaban medio desnudos y sin tener con que se cubrir [Crónica del Perú, Pedro Cieza de León (1551)].

c. La más corta y primitiva [oración] es la que en Valencia enseñan las madres a sus niños al levantarlos por la mañana de su cama, y llevándolos medios desnudos y aun medio dormidos [Genio e ingenio del pueblo andaluz, Fernán Caballero (1836)].

d. el movimiento de la nueva vida que comienza a extenderse desde el corazón a las extremidades de la península; verá sus hijos vagar medios desnudos por estos callejones, y crecer bravíos entre la cultura y el lujo [Pedro Sánchez, José Ma de Pereda (1870)].

(5) a. ella alego que quien iba a ocuparse del pobre Tony, el menor de mis medio hermanos, y de la casa [Novios de antaño, María Elena Walsh (Argentina, 1990)].

b. fue capaz de alimentarse tragando todas las porquerías que recogía en los tachos de basura y que disputaba a los mendigos y perros. En tanto que sus medio hermanos morían como moscas, tuberculosos o intoxicados [La tía Julia y el escribidor, Mario Vargas Llosa (Perú, 1977)].

c. un padre nos ha engendrado, una madre nos parió; a los demás no les cabe de mi deshonra y baldón sino sola la mitad, mis medios 
hermanos son [Los cabellos de Absalon, Pedro Calderón de la Barca (1640)].

d. Los hermanos pueden ser carnales o medios hermanos. Se denominan carnales los hermanos que lo son por parte de padre y por parte de madre; y medios hermanos, los que son simplemente paternos o maternos [Código Civil de Ecuador, Art. 26 (1970)].

a. Lejos de aplacar a doña Rosa el convencimiento de que Cecilia Valdés era hija adúltera de su marido y medio hermana por ende de su desgraciado hijo, eso mismo pareció encenderla en ira y en el deseo desapoderado de venganza [Cecilia Valdés o La loma del Ángel, Cirilo Villaverde (Cuba, 1853)].

b. Si era directora, era por algo; a un cargo así no se llega de balde -según entendidos, era media hermana del ministro de la educación [Cuentos, Guido Rodríguez Alcalá (Paraguay, 1993)].

\section{LA RECATEGORIZACIÓN DE MEDIO Y SU INTERPRETACIÓN SEMÁNTICA}

El proceso sufrido por medio, conocido en la literatura como recategorización (cf., desde diferentes perspectivas de análisis, los trabajos de Lyons 1971: 277, Company 1995, Dubinsky y Williams 1995, Rafel 2000, Demonte 2001, Stulic 2003, etc.), hace referencia al hecho de que un elemento se interpreta en unas variedades como una categoría gramatical (como adjetivo en el caso de medio) y en otras variedades como otra categoría $(\text { adverbio })^{9}$.

9 El término recatergorización ha sido utilizado por diversos autores y en diferentes teorías gramaticales, y no siempre con el mismo significado. Así, por ejemplo, la llamada 'relationchange' de Dowty (1982) corresponde a la noción de 'recategorization' en Egli y Egli-Gerber (1991). Otros autores, en cambio, se refieren a la 'recategorization' como el proceso que redefine las propiedades inherentes del nombre (cf. Corbett 2000: 81, y desde un punto de vista morfológico, Štekauer 1996: 23-43 y Plag 2003), y en ciertas disciplinas, como en la Syntax of Construction (cf. Malchow 1992), forma parte central de su análisis. Emplearemos, por ello, el término recategorización en el sentido de 'conversión' (cf. Demonte 2000, 2001). 
Para conocer los patrones semánticos y morfosintácticos que causan la recategorización de medio en español, y cómo se ha adaptado dicha conversión, resulta necesario revisar en primer lugar la interpretación semántica de esta forma. El significado más común y aceptado de medio, como adverbio, es el de 'no del todo', 'no enteramente' (El pollo está medio asado). Sin embargo, medio compite en la actualidad, y ha competido desde antiguo, con otros adverbios y locuciones adverbiales que presentan un significado muy similar, como la mitad de, a medias, a la media (cf. 9), (los) medios/ meyos (cf. 7 y 8) ('no del todo', 'no enteramente', 'casi enteramente', 'algo, no exactamente la mitad', 'la mitad cada uno', etc.), de ahí que en ocasiones resulte complicado distinguir la interpretación de uno y otro (dormido a medias vs. medio dormido). En general, tal y como indica Bosque (1999b), medio puede combinarse con cualquier nombre, pero cuando éste es consabido se emplea mitad. La diferencia semántica, por tanto, reside en que cuando la partición es de entidades el resultado es un fragmento de esa entidad. En cambio, si la partición es de cantidades, el resultado obtenido es otra cantidad:

a. començó él a renovar sus marauillas, dando tan fuertes y mortales golpes que de más de treinta cavalleros que eran, ya tenía los medios muertos. Y si el gran gigante no le acossara tanto, él entendiera de librarse presto dellos [Espejo de príncipes y caballeros, Diego Ortúñez de Calahorra (1555)].

b. y como todos acabaron de llegar, tentó la tierra, buscando pan y oro. Matáronle veinte compañeros los indios con saetas de yerba. Dejó allí los medios españoles, y con los otros medios fue al cabo del Mármol, donde hizo una fortalecilla para repararse de los indios flecheros [Historia General de las Indias, Francisco López de Gómara (1538)].

c. aquellos a quienes Jesús no se confía, es a saber, de los medios cristianos que no pasan de la clase de los catecúmenos [Predicación del Evangelio en las Indias, José de Acosta (1570)].

a. De piedras \& de dardos; yuan grandes nuuadas. Con los almoianeges; dauan grandes golpadas. Que auien delas torres; mas de las medias aplanadas. Mas las yentes de dentro; eran tan denodadas. Que tenien los de ffuera; dela uilla redradas [Libro de Alexandre].

b. \& si no partan los en esta manera. el marido que aya sus heredades \& eylla las suyas. E si ouieren alguna heredat comprada o 
guanadaque partan por meyos. El mueble \& las deudas que partan por meyo. E si por auentura creaturas dobladas ouieren. el padre prenda la meatad. \& la madre la otra [Fuero General de Navarra, versión B].

c. el rey echelo dela tierra. \& emparelj quoanto oujere. \& espere \& suffra enemiçtat de sus parientes. \& si forçare meior de ssj. deue. detos. sueldos los meyos poral Rey. los otros meyos pora la forçada. El Rey sobre esto deuelo echar de tierra. \& suffra enemjçtat delos parientes deylla. si la fuerça [Fuero General de Navarra, versión B].

(9) a. El dia 28 salieron mas de seicientos hombres de la Ciudad para Churubamba, hasta mas arriba del campamento de Tupac Amaru que es a la media cuesta del camino de Lima [Documentos de Bolivia, (Alto Perú)].

b. El dia 1 de Agosto fue el Señor Segurola al campamento del Sr. Flores y se volvio en el mismo dia, Arrearon mucho ganado menor a la Ciudad; venian escoltando los blanquillos y cochabambinos; se aparecieron en media cuesta de Potosi los alzados [Documentos de Bolivia (Alto Perú)].

(10) a. Tenía las piernas, de los medios muslos abajo, embijados de lo mismo: el rostro de hombre mozo y muy bien contrahecho, y una máscara con tres vetas de espejuelo y dos de oro que le atravesaban el rostro [Relación de Tezcoco, Juan Bautista Pomar (1562)].

b. se reforçó y hizo más cruel y sangrienta la batalla. Los unos y los otros andavan peleando, el agua a medios muslos y a la cinta, con mucha dificultad y aspereza que avía para andar por ella, por las malezas de çarças y matas y árboles caídos [La Florida, El Inca Garcilaso de la Vega (1578)].

c. es de tan grande virtud contra todos géneros de ponzoña, que untándose con el zumo de esta yerba machacada o refregándose con ellas los brazos y de medio muslo abajo todas las piernas, quedan para siempre preservados que no les puede morder ni picar víbora [Compendio y descripción de las Indias Occidentales, Antonio Vázquez de Espinosa (1600)].

La idea principal de la 'recategorización', esto es, del hecho de que siendo un adverbio medio se comporte como un adjetivo y concuerde con el elemento al que acompaña, como vemos en los ejemplos de 11 y 12, 
se relaciona de manera crucial con la interpretación semántica de dicha categoría (Malchow 1992: 32):

¿Cómo estái? ¿Y la señora...? ¿Con quién fue que te casaste?... Ah, sí, los conozco, son medios parientes de la Berenice. ¿Así que te ha ido bien? ¡Qué bueno, hombre! [Casa de campo, José Donoso (Chile, 1978)].

(12) a. - ¿Y no le convendría a él irse a trabajar allá? INF.-Mira, es que a mí no me gustan los guatones, oye. No me gustan, no sé, los hallo como gelatina media cuajada, ¿me entendís?, como ni chicha ni limonada. -Ya. INF.-Así es que... [Habla Culta de Santiago de Chile, M25].

b. de competencia de... de... de persona a persona. Y no era así. Entonces, dos... me llegaron dos o tres alfilerazos, y, como te digo, yo soy media... media picada, ¿ah?...-¡Ah, ya! INF.-...entonces, no quiero tener que pelear con nadie, salvo que me sintiera motivada, ¿ves? [Habla Culta de Santiago de Chile, M9].

En efecto, la semántica del nombre o del adjetivo 'acompañado' parece condicionar el cambio de categoría de medio. La mayoría de los nombres y adjetivos de nuestro corpus siempre ofrecen una información, cualidad o característica negativa del sujeto, tanto en los ejemplos registrados con medio: (m. sg.) ciego, crudo, despierto, enterrado, muerto, pasmado, tonto; (m. pl.) borrachos, cerrados, muertos, parientes, salvajes; (f. sg.) boba, desnuda, llena, muerta, podrida, vestida; (f. pl.) desnudas, muertas, vestidas; como cuando aparece la recategorización: 'media' (f. sg.) confusa, cuajada, desnuda, hermana, lerda, muerta, mujer, pesimista, picada, rara; 'medios' (m. pl.) amigos, cristianos, dioses, hermanos, hombres, judios, raros, tontos; y 'medias' (f. pl.) pasadas, personas:

(13) a. [...] mientras estaba trabajando, conocí a mi marido. -Ah, ya había dejado al otro. INF.-Dejé al otro y me casé con mi marido. Una cosa así media rara, ¿no? Y bueno... [Habla Culta de Buenos Aires, M5].

b. INF.A -A Pedagogía. INF.B -A Pedagogía. INF.A -No; es que hay otra... otra división dentro del... INF.B -Sí, porque eso... me tiene media confusa a mí. INF.A -...dentro de la Facultad. Está estructurada de la siguiente manera: de primero a tercer año, depende de... [Habla Culta de Santiago de Chile, M6]. 
c. INF.A. -Mira, fíjate que en eso, yo, el año pasado, no sé si... o este año, creo que fue, no sé si estaría media pesimista, pero me acuerdo que lo dije, y lo sigo afirmando, de que acá, en Chile, nosotros... cada cinco años tenemos terremotos físicos [Habla Culta de Santiago de Chile, M35].

d. [...] lo dejo en el velador, ¿mm?, pero yo no me lo puse, entonces: "QQué va a ser de mi anillo!" Tenía dos teorías: o la empleada nueva, que tú ves que es media lerda, debe haberlo lanzado cuando limpia la pieza, o los nietos me lo tomaron [Habla Culta de Santiago de Chile, M43].

Se trata, por tanto, de calificativos despectivos (muerta, rara, tonta, lerda, picada) que presentan un sentido 'modal' gracias a que medio matiza el carácter negativo de los mismos, al graduar esa intensión con el valor de 'un poco, algo'. De este modo, y por razones de cortesía, cuando no se necesita o no se desea resaltar la condición peyorativa del sujeto los hablantes emplearían medio. No obstante, desde un punto de vista categorial, el fenómeno sigue el camino previsto por la marca de género; esto es, del masculino al femenino y del singular al plural. Como vemos en la Tabla 2 (cf. infra), mientras el femenino singular (medio $+-a$ / media) es de uso normal, el plural (medio +- as/medias) parece estar menos aceptado.

Tabla 2. Distribución de medio (forma estándar vs. forma vernácula)

\begin{tabular}{lrrrr}
\hline Estándar & Porcentajes & & Vernácula & Porcentajes \\
1. medio $+-a$ & $14.29 \%(11)$ & vs. & media $+-a$ & $41.56 \%(32)$ \\
2. medio $+-o s$ & $10.39 \%(8)$ & vs. & medios $+-o s$ & $25.97 \%(20)$ \\
3. medio $+-a s$ & $5.19 \%(4)$ & vs. & medias $+-a s$ & $2.60 \%(2)$
\end{tabular}

Estos porcentajes muestran además el grado de estabilidad de la recategorización: en plural medias hermanas no es una recategorización convencional en español $(2.60 \%)^{10}$, en cambio media hermana $(41.5 \%)$ y medios hermanos (25.9\%) sí lo son. Desde un punto de vista léxico, se puede buscar una explicación para esta distribución; por ejemplo, mientras

10 Medio puede concordar con el sujeto si acompaña a otro adverbio (Ella está media $\mathrm{mal}$ ), pero en contra de la coordinación nominal, en nuestro corpus no documentamos casos del tipo ?media hermanas. 
los centauros pueden ser 'medios hombres medios caballos' (cf. 14), las sirenas no son 'medias mujeres medias peces':

(14) Uiendo que corrien tanto \& los veyan a cauallo cosa muy inusitada afirmauan que aquellos fuesen medios onbres e medios cauallos. Tanto atemoraron las gentes en sus prinçipios que no sola mente defendieron su tierra. mas ganaron la agena de sus vezindades [Fernando Mejía].

Como se ha podido ver en los ejemplos precedentes, en este caso la recategorización permite caracterizar de un modo [ \pm valorativo] el objeto de discurso en cuestión, restar especificidad a un término negativo (lerda, tonta) y hacerlo más 'suave', lo que implica una nueva conceptualización de la palabra y su posterior conversión, como se refleja en esta secuencia:

recategorización $=$ nueva conceptualización del término $>$ conversión

Este es un proceso gramatical general que se da en todo el español, de ayer y hoy. La evolución de otros adverbios que eran adjetivos en la lengua antigua, por ejemplo el caso de alerta/ alerto (cf. 15a) y solo/sola (cf. 15b), presenta un patrón muy similar:

(15) a. ninguno se sube a imaginar lo que no es; ni le puede valer ser importuno, ni pensar, ni mirar, ni estar alerto, si le huyen los hados uno a uno. Arrástranle durmiendo y aun despierto, y llévanle tras sí por los cabellos sin que le valga seso [Poesía, Diego Hurtado de Mendoza (1538)].

b. Varones había que remudaban mujeres sin aguardar a que se muriesen. La gente que entre ellos era común y plebeya se contentaba con tener sola una mujer [Prosistas de la Colonia, ss. XV-XVIII (Puebla, México)].

En español actual podríamos citar también el caso de puro (cf. 16) o demasiado (cf. 17):

(16) a. [...] llegada esta gente, salí a conquistar la tierra, y constreñí tanto a los naturales rompiéndoles todos los fuertes que tenían, que de puros cansados y muertos de andar por las nieves e bosques, como alimañas brutas, vinieron a servir, e nos han servido hasta el día de hoy [Cartas del Reino de Chile, Pedro de Valdivia (1527)]. 
b. Era muy sabroso, muy, bueno, eso sí, de eso... no lo cambiamos nunca. Pero no me casé por pura perezosa, por todo, pues. X. habría sido gran persona, y hoy está pensionado que eso era lo que debía de haber buscado [Habla Culta de Bogotá, M38].

(17) a. Mi opinión es que es demasiado avanzada. Vamos en la era, bueno, de avance. Demasiada avanzada, porque yo estoy acostumbrada... allí la juventud de Cuba era más tranquila. Iba a fiestas, iba a bailes, hacía maldades... [Habla Culta de La Habana, M11].

b. -Claro...en la carrera mía de música yo tuve una cosa en contra mí y fue que terminé la carrera demasiada joven. Yo con catorce años había terminado la música [Habla Culta de La Habana, M8].

En resumen, según señala Bosque (1990: 127), como adverbio medio es un circunstante que sitúa la significación del verbo en una coordenada espacial, o añade información que complementa la estructura argumental del predicado; como adjetivo, en cambio, actúa igual que un predicado, posee flexión y califica al nombre.

\section{CONSIDERACIONES FINALES}

El objetivo principal de este trabajo ha sido el de dar a conocer un proceso de recategorización en español: la conversión del adverbio medio en adjetivo. He presentado, gracias a los datos del ALPI, la distribución espacial de medio/ media en el castellano peninsular (Mapa y Tabla 1), y he considerado que estos datos pueden arrojar también luz nueva sobre la aparición del fenómeno en las variedades americanas, entendidas estas como el producto de una nivelación de variantes, debido a su presencia en los dialectos del sur.

Por otro lado, según la documentación presentada, ni la conversión de medio ni la variación (medio/ media) son aspectos nuevos en el español actual. En efecto, la recategorización es un proceso de cambio en las lenguas que es posible documentar desde época medieval. Tampoco debe ser tratado como un fenómeno aislado, ya que existen otros ejemplos de recategorización con diversos adverbios (por ejemplo puro y demasiado), del mismo modo que es posible el cambio inverso, cuando algunos adjetivos toman funciones adverbiales (cantó lindo, trabaja duro). Por último, el 
fenómeno de vacilación (sub)categorial muestra que la alternancia es un rasgo característico del español y que puede registrarse en el habla de un mismo individuo.

\section{REFERENCIAS BIBLIOGRÁFICAS}

Alonso, Amado. 1961/1953. La base lingüística del español americano. En Estudios lingüísticos. Temas hispanoamericanos, pp. 7-60. Madrid: Gredos.

Bello, Andrés. 1988/1847. Gramática de la lengua castellana. Destinada al uso de los americanos. Santiago de Chile: Imprenta del Progreso. Reimp. Gramática de la lengua castellana destinada al uso de los americanos. Con las notas de Rufino José Cuervo. Madrid: Arco/ Libros.

Bhat, D. N. Shankara. 1994. The Adjectival Category. Amsterdam: John Benjamins.

Bosque, Ignacio. 1990. Las categorías gramaticales. Relaciones y diferencias. Madrid: Síntesis.

1999a. El sintagma adjetival. Modificadores y complementos del adjetivo. Adjetivo y participio. En Ignacio Bosque y Violeta Demonte (dirs.). Gramática Descriptiva de la Lengua Española, vol. 1, pp. 217-310. Madrid: Espasa.

1999b. El nombre común. En Ignacio Bosque y Violeta Demonte (dirs.). Gramática Descriptiva de la Lengua Española, vol. 1, pp. 3-75. Madrid: Espasa.

Boyd-Bowman, PetTer. 1956. The regional origins of the earliest spanish colonists of America Papers of the Modern Linguistic Association 80: 1152-1172.

1964. Índice geobiográfico de cuarenta mil pobladores españoles de América en el siglo XVI. Vol. 1. Bogotá: Instituto "Caro y Cuervo".

-1985. Índice geobiográfico de más de 56 mil pobladores de la América hispánica, (1493-1600). México: Fondo de Cultura Económica.

Company Company, Concepción. 1995. Old forms for new concepts. The recategorization of possessive duplications in Mexican Spanish. En Henning Andersen (ed.). Historical Linguistics 1993, pp. 77-92. Amsterdam: John Benjamins.

Corbett, Greville G. 2000. Number. Cambridge: Cambridge University Press.

Corominas, Joan. 1944. Indianorrománica. Revista de Filología Hispánica VI: 139-175 y 209-254.

1980. Diccionario crítico etimológico castellano e hispánico (con la colaboración de J. A. Pascual). Madrid: Gredos.

Cotarelo Valledor, Armando. 1927. El castellano en Galicia. Notas y observaciones. Boletín de la Real Academia XIV: 82-136.

Cuervo, Rufino José. 1885. Apuntaciones críticas sobre el lenguaje bogotano. Chartres: Imprenta de Durand. 
1998/1886. Diccionario de Construcción y Régimen de la Lengua Castellana. Barcelona: Herder/ Instituto "Caro y Cuervo".

Davies, Mark. 2001-2005. Corpus del español. Provo: Brighman Young University.

Demonte Barreto, Violeta. 2000. Gramática, variación y norma. Una tipología. Estudios Hispánicos. Revista de la Sociedad Coreana de Hispanistas 17/12: 3-49.

2001. El español estándar (ab)suelto. Algunos ejemplos del léxico y la gramática. En Actas del II Congreso Internacional de la Lengua Española, Madrid: RAE/ Instituto Cervantes [en línea]. Disponible en http://cvc.cervantes.es/obref/congresos/valladolid/ [Consulta 10/07/2010].

Dowty, DAVID. 1982. Grammatical Relations and Montague Grammar. En Pauline Jacobson y Geoffrey K. Pullum (eds.). The Nature of Syntactic Representation, pp. 79-130. Dordrecht: Riedel.

Dubinsky, Stanley y Kemp WiLliams.1995. Recategorization of prepositions as complementizers. The case of temporal prepositions in English. Linguistic Inquiry 26: 125-137.

Egli, Urs y Renata Egli-Gerber. 1991. Sprachsysteme-logische und historische Grundlagen der erweiterten Phrasenstrukturgrammatik. Konstanz: Fachgruppe Sprachwissenschaft.

Fernández-Ordóñez, InÉs. 2004-2010. Corpus Oral y Sonoro del Español Rural (COSER). Madrid: Universidad Autónoma de Madrid.

García, Constantino. 1985. Temas de lingüística galega. Coruña: La Voz de Galicia.

García, Constantino y Luisa Blanco. 1998. El castellano de Galicia. Interferencias lingüisticas entre gallego y castellano. Madrid: Anaya.

Graell Stanziola, Matilde y Antonio Quilis. 1991. Datos sobre la lengua española en Panamá. En César Hernández Alonso et al. (eds.). El Español de América. Actas del III Congreso Internacional de El Español de América, vol. 2, pp. 997-1005. Salamanca: Junta de Castilla y León.

Henríquez Ureña, Pedro. 1925. El supuesto andalucismo de América. Cuadernos del Instituto de Filología de Buenos Aires I/2: 114-122.

Hooper, Paul J. y Sandra A. Thompson. 1984. The discourse basis for lexical categories in universal grammar. Language 60: 703-752.

Kany, Charles E. 1962 [1960]. Semántica hispanoamericana. Madrid: Aguilar. 1970 [1945]. Sintaxis hispanoamericana. Madrid: Gredos.

Labov, William. 1972. Some principles of linguistic methodology. Language in Society 1/1: 97-120.

1974. On the Use of the Present to Explain the Past. En Luigi Heilmann (ed.). Proceedings of the $11^{\text {th }}$ International Congress of Linguistics, pp. 825-851. Bologna: Societá Ed. Il Mulino.

LAPESA, RAFAEL. 1964. El andaluz y el español de América. En Presente y Futuro de la Lengua Española, vol. II, pp. 173-182. Madrid: Editorial Cultura Hispánica.

LAUWERS, PETER. 2004. Recategorization and constructions: The case of copular sentences with bare nouns in French. Ponencia presentada en The Lexicon: Its Status in the Theory of Language, The Linguistic Association of Finland, Turku, Finlandia, 18-19 de noviembre de 2004.

Lope Blanch, Juan Manuel. 1972. Estudios sobre el español de México. México: UNAM.

Lyons, JoHn. 1971. Introduction to Theoretical Linguistics. Cambridge: Cambridge University Press.

Malchow, Anne. 1992. Syntax and Semantics of Construction. Konstanz: Fachgruppe Sprachwissenschaft.

MartíneZ, José Antonio. 1999. La concordancia. En Ignacio Bosque y Violeta Demonte (dirs.). Gramática Descriptiva de la Lengua Española, vol. 2, pp. 2695-2786. Madrid: Espasa. 
MEnÉndeZ PidAL, RAmón. 1962. Sevilla frente a Madrid. Algunas precisiones sobre el español de América. En Diego Catalán (ed.). Estructuralismo e historia. Miscelánea homenaje a A. Martinet, vol. III, pp. 99-165. Madrid: Gredos/ La Laguna: Universidad de La Laguna.

Meyer-Lübke, Wilhelm. 1974/1899. Grammaire des langues romanes, Vol. III: Syntaxe. Ginebra: Slatkine Reprints.

Moreno de Alba, José G. 1993. El español en América. México: Fondo de Cultura Económica.

Quilis, Antonio. 1983. La concordancia gramatical en la lengua española hablada en Madrid. Madrid: CSIC.

Pato, EnRique y David Heap. 2005. The lexical-syntactic process of recategorization: the case of Spanish medio. En Claire Gurski (ed.). Proceedings of the 2005 Canadian Linguistics Association Annual Conference, pp. 1-9. London: The University of Western Ontario.

Plag, Ingo. 2003. Word-formation in English. Cambridge: Cambridge University Press.

Rabanal, Manuel. 1967. Gramática breve del castellano hablado en Galicia y otros temas. En Hablas hispánicas. Temas gallegos y leoneses, pp. 11-69. Madrid: Alcalá.

RAFEL, JOAN. 2000. Recategorización de complementante a preposición. En Annick Englebert et al. (eds.). Actes du $22^{e}$ Congrès de Linguistique et Philologie Romanes, vol. VI, pp. 427-436. Tübingen: Max Niemeyer.

Real Academia Española. 1972. Esbozo de una Nueva Gramática de la Lengua Española. Madrid: Espasa-Calpe.

2005. Diccionario panhispánico de dudas. Madrid: Santillana/RAE.

2010. Nueva gramática de la lengua española. Madrid: RAE/Espasa.

Rojo, Guillermo. 2004. El español de Galicia. En Rafael Cano (coord.). Historia de la lengua española, pp. 1087-1101. Barcelona: Ariel.

Seco, Manuel. 1986. Diccionario de dudas y dificultades de la lengua española. Madrid: Espasa-Calpe.

Štekauer, Pavol. 1996. A Theory of Conversion in English. Frankfurt: Peter Lang.

Stulic, ANA. 2003. Judeo-Spanish 'syendo': from gerund to causative conjuction. Ponencia presentada en el XVIth International Conference on Historical Linguistics, Copenhage, Dimanarca, 11-15 de agosto de 2003.

Wagner, Max LeOPold. 1920. Amerikanisch-Spanisch und Vulgärlatein. Zeitschrift für romanische Philologie XL: 286-312 y 385-404.

1927. El supuesto andalucismo de América y la teoría climatológica. Revista de Filología Española XIV: 20-32.

Wetzer, Harrie. 1996. The Typology of Adjectival Predication. Berlín: Mouton de Gruyter.

WiJK, HENRI van. 1969. Algunos aspectos morfológicos y sintácticos del habla hondureña. Boletín de Filología de la Universidad de Chile XX: 3-16. 